\title{
Variability of Winter Storminess in the Eastern United States during the Twentieth Century from Tide Gauges
}

\author{
PHILIP R. THOMPSON* AND GARY T. MitCHUM \\ College of Marine Science, University of South Florida, St. Petersburg, Florida \\ CEDRIC VONESCH \\ Biomedical Imaging Group, Ecole Polytechnique Fédérale de Lausanne, Lausanne, Switzerland \\ JIANKE LI \\ IMSG, and NOAA Coral Reef Watch, Silver Spring, Maryland
}

(Manuscript received 31 July 2012, in final form 12 July 2013)

\begin{abstract}
Interannual to multidecadal variability of winter storminess in the eastern United States was studied using water level measurements from coastal tide gauges. The proximity to the coast of the primary winter storm track in the region allows the use of tide gauges to study temporal modulations in the frequency of these storms. Storms were identified in high-passed, detided sea level anomalies in 20 gauges from all coasts of North America to assess variability in winter storminess along particular storm tracks. The primary result is a significant multidecadal increase in the number of storms affecting the southeastern United States from the early to late twentieth century. The authors propose that this change is due to an increased tendency for the jet stream to meander south over the eastern United States since the 1950s. This mechanism is supported by longterm changes in the large-scale sea level pressure pattern over North America. The nature of the multidecadal change in storm frequency is unclear, because limited tide gauge record lengths prevent distinguishing between a trend and an oscillation.
\end{abstract}

\section{Introduction}

A primary winter cyclogenesis region over North America is the western Gulf of Mexico (GOM) (Lewis and Hsu 1992; Wang et al. 1998). Extratropical storms originating in the GOM often propagate northeast along the Atlantic coast of the United States affecting many dense population centers and important agricultural regions. The impact of such storms can be extensive as they tend to produce more precipitation and possess stronger winds than average (Businger et al. 1990; Hirsch et al. 2001). It is therefore important to understand the time scales and

\footnotetext{
* Current affiliation: Department of Oceanography, University of Hawaii at Manoa, Honolulu, Hawaii.

Corresponding author address: Philip R. Thompson, Department of Oceanography, University of Hawai'i at Mãnoa, 1000 Pope Rd., MSB 317, Honolulu, HI 96822.

E-mail: philiprt@hawaii.edu
}

mechanisms of variability in activity along this particular storm track and assess relationships with other important North American cyclogenesis regions such as the lee of the Appalachian Mountains (Petterssen 1941, 1950).

A prominent example of winter cyclogenesis in the GOM occurred in March 1993, when a powerful storm known as the Storm of the Century (SOC) formed in the GOM and followed the Atlantic North American coast to the northeastern United States. The storm caused 1.6 billion dollars in property damage and at least 47 deaths in Florida alone (Kocin et al. 1995). The SOC influenced unusually large spatial scales, which is demonstrated by the estimated 90 million people in the United States who experienced at least an inch of snow (Kocin et al. 1995). The impact of the SOC was partially due to the size and intensity of the storm, but the storm track was equally important. The track of the SOC shown in Fig. 1 enabled the storm to interact with energy sources in the GOM and the Gulf Stream, as well as impact a maximum land area and population. 


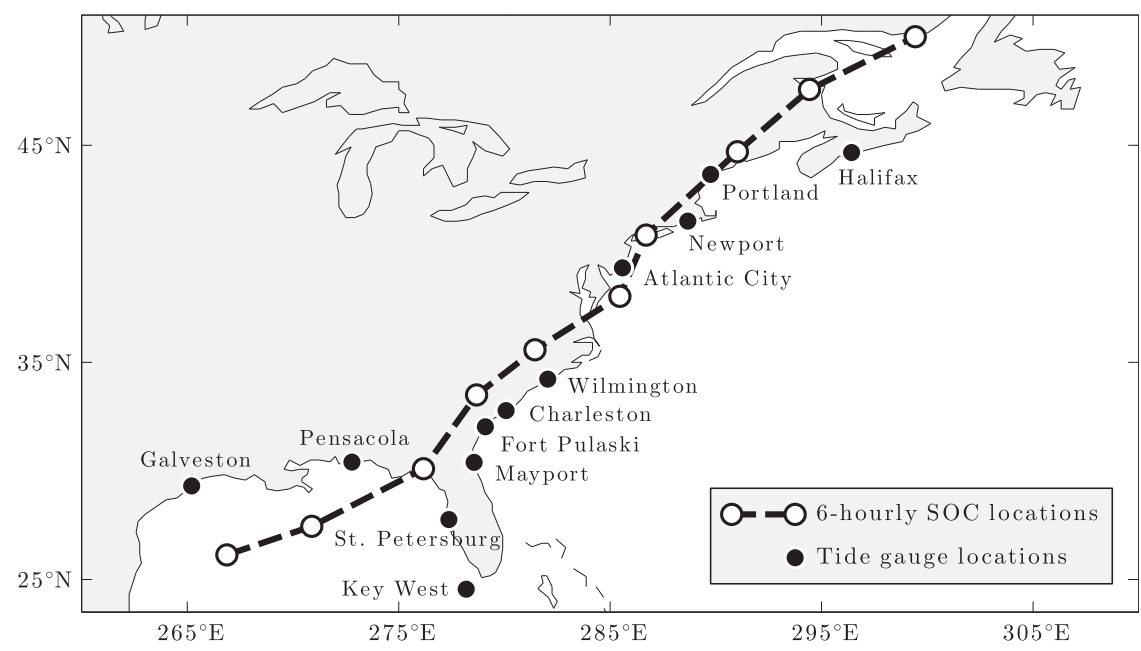

FIG. 1. The SOC track at 6-hourly intervals (white circles) beginning with 1200 UTC 12 Mar 1993 in the GOM and the location of tide gauges (black circles).

A substantial body of literature is devoted to documenting and categorizing winter storms on the GOM coast and East Coast of the United States. Some of these studies describe temporal changes in storm frequency or character, and some assess relationships between variability in storminess and climate variables. The majority of research is focused on decadal-scale secular trends and/ or interannual variability in the context of the El NiñoSouthern Oscillation (ENSO). Secular trends are of particular interest given the current focus on long-term climate change, and many climate models make specific predictions about the impact of climate change on storm tracks and intensity (e.g., Yin 2005; Bengtsson et al. 2006).

The earliest studies of winter storm variability in the United States fall into two categories. The first relied on subjective identification of storms in meteorological data, and the second relied on analyses of financial data. Hosler and Gamage (1956) found no significant trend from 1905 to 1954 in U.S. storm frequency or track; however, they emphasized that the task of defining and tracking storms changed hands multiple times during the record. A different conclusion was reached by Mather et al. (1964), who found the frequency of damaging storms based on dollar amounts rose from 2-3 per year in the 1920s and 1930s to more than 7 per year in the 1960s. They too noted limitations in their methods, citing the difficulty of using financial data to assess changes in the physical climate. Subsequent studies of meteorological data identified a decrease in total U.S. storm frequency during the 1950s through the 1970s (Reitan 1979; Zishka and Smith 1980; Whittaker and Horn 1981; Davis et al. 1993), but Carter and Draper (1988) suggested an increase in total storminess from 1962 to 1985 based on annual mean significant wave height in the North Atlantic.
A different approach is to focus on variability in specific storm types or tracks instead of the total number of storms. Hayden (1981) found a trend toward increased cyclone frequency over marine areas and decreased cyclone frequency over continental areas from the late nineteenth century through the 1970s with a peak in the late 1950s. Their results imply an increase during the early to middle twentieth century in activity along the SOC storm track. A potential mechanism for the increase in maritime cyclones is an intensified baroclinic zone at the U.S. East Coast associated with an injection of polar air over the continental United States (Resio and Hayden 1975; Dickson and Namias 1976).

More recently, the advent of quality gridded meteorological datasets provided a means to objectively identify and track storms. Hirsch et al. (2001) created a climatology of East Coast winter storms in the National Centers for Environmental Prediction-National Center for Atmospheric Research (NCEP-NCAR) reanalysis over the period 1951-97. They found a nonsignificant decreasing trend in East Coast storminess and no trend in "full coast storms," which include storms that follow the SOC track. On interannual scales, studies of gridded products identified ENSO as the dominant mode of interannual variability in storminess over eastern North America (Hirsch et al. 2001; Schubert et al. 2005; Eichler and Higgins 2006). Furthermore, there is clear evidence of a relationship between ENSO phase and activity along the SOC track in particular. For example, Eichler and Higgins (2006) found GOM cyclogenesis occurred more often during warm ENSO phase and storm frequency increased (decreased) over the SOC track during warm (cold) ENSO phase winters. Their results are consistent with others who found similar 
relationships between ENSO phase and storm activity in the region of the SOC track (Noel and Changnon 1998; Hirsch et al. 2001; Schubert et al. 2005). The ENSO teleconnection with storminess in the eastern United States occurs via strengthening of the southern branch of the jet stream over North America (Smith et al. 1998) and an increase in sea surface temperature in the GOM and southeastern U.S. coastal regions (DeGaetano et al. 2002).

Despite the advantages of modern meteorological products, they are not suitable for analyses of multidecadal variability in storminess, because they are limited temporally to the second half of the twentieth century. Moreover, meteorological instrumentation was largely developed for the study of weather and not climate. This means leveling data across instrumentation changes was not a priority, which makes analyses of multidecadal variations in storminess difficult in older meteorological data. However, an alternative and independent method to study storminess in coastal regions exists because of the effect of storms on local sea level at tide gauges. The advantages of using tide gauges to study storminess include long record lengths extending to the early part of the twentieth century and methods that remain essentially unchanged. Certainly the tide gauge dataset introduces its own set of limitations (e.g., spatial distribution), but storminess along the GOM and Atlantic coasts of the United States is uniquely suited for such an analysis. There are many high-quality, long tide gauge records and most storms impact multiple gauges. Storm activity along the SOC track is notably appropriate because of interaction with coastal areas reaching from the GOM to Nova Scotia (Fig. 1).

Zhang et al. (2000) studied storminess in hourly sea levels from a set of East Coast tide gauges concentrated largely in the northeastern United States. They identified storms by isolating positive storm surges above a predetermined threshold, and they found no significant trend in extratropical storm frequency or intensity during the twentieth century. Kennedy et al. (2007) used daily tide gauge sea levels to investigate interannual variability of winter storminess in the northern and eastern GOM. They found increased (decreased) variance in GOM wintertime daily sea levels during warm (cold) ENSO phase winters, which they related to the previously cited influence of ENSO on GOM cyclogenesis. Sweet and Zervas (2011) studied winter storm surge frequency at various thresholds in the U.S. midAtlantic and Northeast coasts and found a significant increase in positive surges during warm ENSO phase.

We extended the methods, temporal domain, and spatial domain of existing studies in the literature to investigate not only temporal changes in storminess in
TABLE 1. Tide gauges divided into five geographic regions. For each gauge, the year of the first winter (November-April) sea level value is given, as well as the percentage of missing values. The large percentage of missing data in the Ketchikan record is largely due to a single extended period of missing data in the 1930s and 1940s. Only $6.13 \%$ of winter sea level values are missing in the Ketchikan time series from 1949 to 2011.

\begin{tabular}{llcc}
\hline \hline Region & \multicolumn{1}{c}{ Location } & Begin & Missing (\%) \\
\hline GOM & Galveston, TX* & 1904 & 03.28 \\
& Pensacola, FL* & 1923 & 03.38 \\
& St. Petersburg, FL & 1947 & 03.84 \\
& Key West, FL* & 1913 & 02.82 \\
SE & Mayport, FL* & 1928 & 02.47 \\
& Fort Pulaski, GA* & 1935 & 05.75 \\
& Charleston, SC* & 1921 & 01.25 \\
& Wilmington, NC* & 1936 & 02.82 \\
NE & Atlantic City, NJ* & 1911 & 06.86 \\
& Newport, RI* & 1930 & 04.73 \\
& Portland, ME* & 1910 & 02.99 \\
\multirow{4}{*}{ SW } & Halifax, Canada* & 1920 & 03.27 \\
& San Diego, CA* & 1906 & 03.91 \\
& Los Angeles, CA* & 1924 & 01.70 \\
& San Francisco, CA* & 1901 & 00.54 \\
NW & Crescent City, CA & 1933 & 10.13 \\
& Astoria, OR* & 1925 & 02.62 \\
& Neah Bay, WA & 1934 & 04.38 \\
& Ketchikan, AK & 1919 & 25.98 \\
& Sitka, AK & 1938 & 00.36 \\
\hline
\end{tabular}

* Denotes record used for low-frequency analysis.

a particular region but also variability in the spatial distribution of winter storm activity along the U.S. GOM and Atlantic coasts during the twentieth century. We sought to reproduce aspects of the studies mentioned above in order to validate our methods and to identify the physical mechanisms underlying the variability in our results.

\section{Storm events in tide gauge sea levels}

\section{a. Tide gauge data}

Hourly tide gauge data were obtained from the Joint Archive for Sea Level (JASL) Research Quality Data Set (RQDS) maintained at the University of Hawai' $i$ Sea Level Center (UHSLC). Gauges were selected to maximize the length and continuity of the data while simultaneously providing the best possible geographic spacing and coverage. Table 1 summarizes the location, beginning, and completeness of each tide gauge record included in the analysis. A total of 20 gauges were chosen, and they were separated into five regions. Gauges along the GOM, Southeast (SE), and Northeast (NE) coasts were used to investigate winter storminess variations in the region of the SOC track. Gauges in the Southwest (SW) and Northwest (NW) regions were 
included in order to distinguish changes in total storminess over the continent from changes along the SOC track. It should be noted that the record from Mayport, Florida, ended in December 2000. The Mayport record was updated through 2008 with data from a gauge $31 \mathrm{~km}$ to the north in Fernandina Beach, Florida. The two raw time series overlap for more than $14 \mathrm{yr}$, and during this period their correlation is 0.99 .

The raw hourly heights from all gauges were inspected thoroughly for suspicious data, and any level shifts were identified and removed. Tides were removed carefully in a multistep process, because we were concerned by the potential for tidal energy to corrupt the analysis on synoptic time scales. First, a preliminary fit of the tidal harmonics to the data was made using the MatLab T_Tide package (Pawlowicz et al. 2002) based on Foreman (1977). The fit was removed and residual outliers greater than five standard deviations about the mean were noted. Tidal fits were then recalculated from the raw data ignoring the outliers. Low-frequency energy well outside synoptic time scales was removed using a convolution high-pass filter. The filter passed at least $90 \%$ of the amplitude at periods shorter than 29 days and less than $10 \%$ of the amplitude at periods longer than 70 days.

These initial processing steps are illustrated for the Mayport record in Fig. 2a. The raw 6-hourly sea levels $h_{\text {raw }}$ are shown with the residuals from the tidal analysis described above $h_{\text {res }}$, which shows that a large fraction of the variance is removed with the tidal fits. This is not necessarily the case at all locations and depends on local geography and proximity to tidal amphidromes. The high-pass-filtered time series $h_{\mathrm{hp}}$ is also shown in Fig. 2a, as well as the low-frequency variability removed by the filter $h_{\mathrm{lp}}=h_{\mathrm{res}}-h_{\mathrm{hp}}$. Comparing $h_{\mathrm{hp}}$ and $h_{\mathrm{lp}}$ demonstrates that the filter primarily removes the long-term trend and interannual to decadal-scale sea level variations, which are of smaller amplitude than the synopticscale variability preserved by the filter.

The high-passed series were then reexamined for suspicious data. Single point spikes in which height values rose and fell more than $50 \mathrm{~cm}$ in consecutive hours were deemed not physical and removed. Close inspection also revealed a ringing at the $M_{2}$ tidal period in some of the time series. The ringing is likely due to timing errors that prevented the tidal fit from sufficiently removing the tidal energy, and it was dealt with in two ways. First, we fit and removed a pair of orthogonal sinusoids at the $M_{2}$ frequency. Second, a 13-point median filter was applied followed by a 5-point triangular filter. The combination of the two techniques removed the ringing and preserved the signature of synoptic-scale variability.

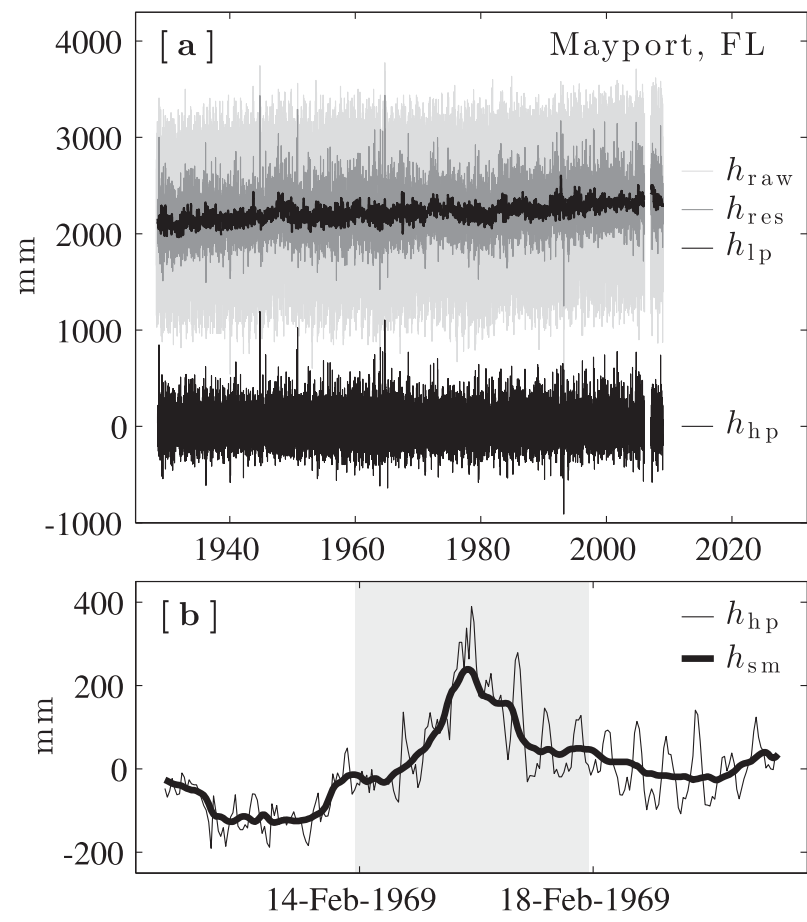

FIG. 2. Example processing of sea level heights from the tide gauge record at Mayport. (a) Quality-controlled 6-hourly heights: $h_{\text {raw }}$ (light gray), tidal residuals $h_{\text {res }}$ (dark gray), variability removed by the high-pass filter $h_{\mathrm{lp}}$ (black top), and the high-pass-filtered heights used in the analysis $h_{\mathrm{hp}}$ (black bottom). (b) Representative ringing at the $M_{2}$ frequency in $h_{\mathrm{hp}}$ (thin black) requiring additional smoothing resulting in the smoothed curve $h_{\mathrm{sm}}$ (thick black).

An example of the residual ringing at the $M_{2}$ period in the high-passed series from Mayport is shown in Fig. $2 b$. The figure shows substantial high-frequency periodic variability, particularly after the synoptic-scale event present at the center of the interval. The time series smoothed by the techniques listed above $h_{\mathrm{sm}}$ demonstrates that the ringing is removed but the signature of the synoptic event remains.

\section{b. Isolating winter storm events}

Our analysis is focused on winter storms, which are extratropical in nature and form along frontal systems. For this reason, we chose to define the winter period to be November through April, which largely excludes nonfrontal tropical storms. It was necessary to avoid including tropical systems, because the dynamics of the two types of storms are quite different, and thus variability in the frequency of the two types of storms is due to different mechanisms. In addition, most extratropical storms, including the most damaging ones, occur during the November through April period (Davis et al. 1993). We note that extratropical storms do occur in nontrivial numbers during October, but this month is also affected by tropical cyclones. Zhang et al. (2000) identified and 


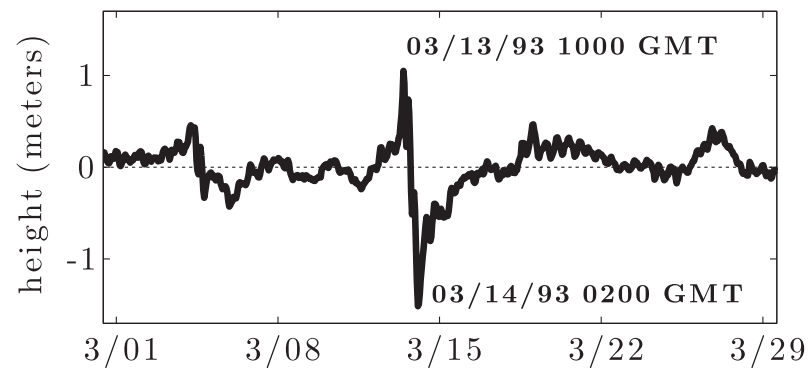

FIG. 3. Tide gauge height series at Charleston, during March 1993. The date and time of the maximum and minimum water levels during the SOC passage are noted.

removed anomalies associated with tropical cyclones from water level data in their analysis. In the interest of simplicity and since the number of extratropical cyclones occurring in October is fewer than any month in the November-April period (Hirsch et al. 2001), we elected to omit the month of October entirely.

In this study winter storm events were identified by searching for the largest height deviations regardless of sign in the high-passed, detided sea level records. Both positive and negative deviations were considered, because the greatest impact of any given storm on local sea level is not necessarily a positive surge. For example, during the passage of the SOC at Charleston, South Carolina, the surge was not as large as the subsequent negative sea level anomaly (Fig. 3). This approach differs from methods previously employed in the literature. Zhang et al. (2000) and Sweet and Zervas (2011) analyzed counts of positive surge events above predetermined thresholds, which may exclude some events in which the effect of a storm was primarily a depression of sea level. This method is best when the primary concern is surge frequency, which is an important quantity for coastal planning applications. Kennedy et al. (2007) formed criteria based on the variance in windows in the time series, but it can be difficult to physically link such criteria to storminess and the criteria may vary geographically. Our decision to count individual storms and to also incorporate large negative sea level deviations does not discriminate between the direction of storm approach and is best when primarily concerned with storm frequency and not surge frequency.

The choice to include negative deviations in our analysis proved valuable, as the largest absolute deviation was negative in a significant fraction of the storm events identified by the procedure described below. The minimum percentage of events identified by a negative anomaly at a single gauge is $25.1 \%$ for Ketchikan, Alaska; the maximum percentage is $63.7 \%$ for Galveston, Texas; and the median for all 20 gauges is $38.5 \%$. There also appears to be some nonrandom geographical structure in the importance of negative surge events. Large negative surges are particularly prevalent in the GOM and SE regions, where more than $45 \%$ of the events at Galveston; St. Petersburg, Florida; Key West, Florida; Mayport; Fort Pulaski, Georgia; and Charleston were identified by negative anomalies. Only one gauge outside the GOM and SE regions, Atlantic City, New Jersey, experienced a percentage of negative events greater than $45 \%$.

In our method the largest deviations were assumed to represent the passage of storms, because synoptic variability is the dominant source of energy at the time scales remaining in the high-passed, detided sea level time series. The difficulty was to determine what constitutes a large deviation, because it was not obvious how to separate local extrema that represented storms from others that were likely to be random anomalies. We referred to the results of meteorological studies to provide an estimate of the average number of storms we should expect to find in any given year. The general consensus from the literature is that the GOM and East Coasts are impacted by 10-12 major extratropical systems during an average winter (Hosler and Gamage 1956; Reitan 1974; Noel and Changnon 1998; Hirsch et al. 2001). Therefore, the number of storm events extracted from each tide gauge record was set equal to 10 times the number of winters with valid hourly data. For example, a tide gauge record of 60 -yr length was assumed to contain 600 winter storm events. No restrictions were placed on the number of storms identified in any individual winter. Only the total number of events identified in each series was fixed. This allowed us to investigate the possibility of nonrandom clumping in the number of storms over time. We use the value of 10 storms per winter as climatology throughout our analysis, and our results are often presented as anomalies about this climatological value.

We tested the dependence of our results on the choice of 10 storms per winter for climatology and found that increasing the number beyond 10 did not substantially change the results. Reducing the number of storms used for climatology did not change the sign but did decrease the amplitude in some cases. The reduction in amplitude is expected as it is likely that not all storms are accounted for in the analysis when using values less than 10 for the climatology.

At each tide gauge we located the largest deviation in the series and called this the first storm event. We then removed the sea level data in a 4-day window surrounding the extreme. Removing the data in a 4-day window insured that a single storm was not counted twice. We then repeat the process to identify the second event, continuing iteratively until the appropriate number of storms was identified. In this fashion we created a database of storm events at each tide gauge. 
The choice to base the number of storms extracted on climatology meant the storm database from tide gauges was not appropriate to assess absolute numbers of storms. Therefore, analyses focused on differences in storm frequency relative to the mean of the gauge or region in question and should not be interpreted as absolute numbers of storms. The advantage of building in the climatology was to minimize the number of random deviations identified as storms, but some misidentified events were inevitably included in our database. For this reason, all calculations in our analysis involved removing the mean and averaging over decades or multiple gauges. Random deviations misidentified as storm events will tend to be removed with the mean, because they are expected to be evenly distributed in time and space. Some regional delineations were chosen based on geography, such as differentiating between the GOM and $\mathrm{SE}$ regions. Other delineations were made based on proximity to cyclogenesis regions, such as the SE and NE regions, which are south and north of the prominent cyclogenesis region in the lee of the Appalachians.

It is also reasonable to consider the effect of coastally trapped waves on the analysis. Coastally trapped waves in response to storm events have the potential to propagate energy from a storm along the coast, which seems contrary to our assumption that the large deviations in sea level are of local origin. The amplitude of the propagating waves, however, is small compared to the response of local sea level. For example, the passage of the winter storm at Charleston in Fig. 3 shows sea level deviations on the order of $1 \mathrm{~m}$ with a time scale of hours. We do not expect that coastally trapped waves would produce the type of extreme deviations we are attributing to the local effect of a strong storm.

\section{Analysis}

Winter storm counts for each gauge in the storm event database are shown in Fig. 4. There are substantial interannual variations in winter storm frequency in all regions, as well as potentially significant low-frequency increases in storm frequency for regions affected by GOM cyclogenesis (GOM and SE). The analysis was partitioned into interannual and decadal time scales, and mechanisms driving the variability were explored. Interannual variability in storminess, particularly that associated with ENSO, is a topic prevalent in the literature and one that is well suited for study using atmospheric data and reanalysis products. We include results from tide gauges at interannual scales primarily to validate our methods against results in the literature and give credence to results at decadal and longer periods.

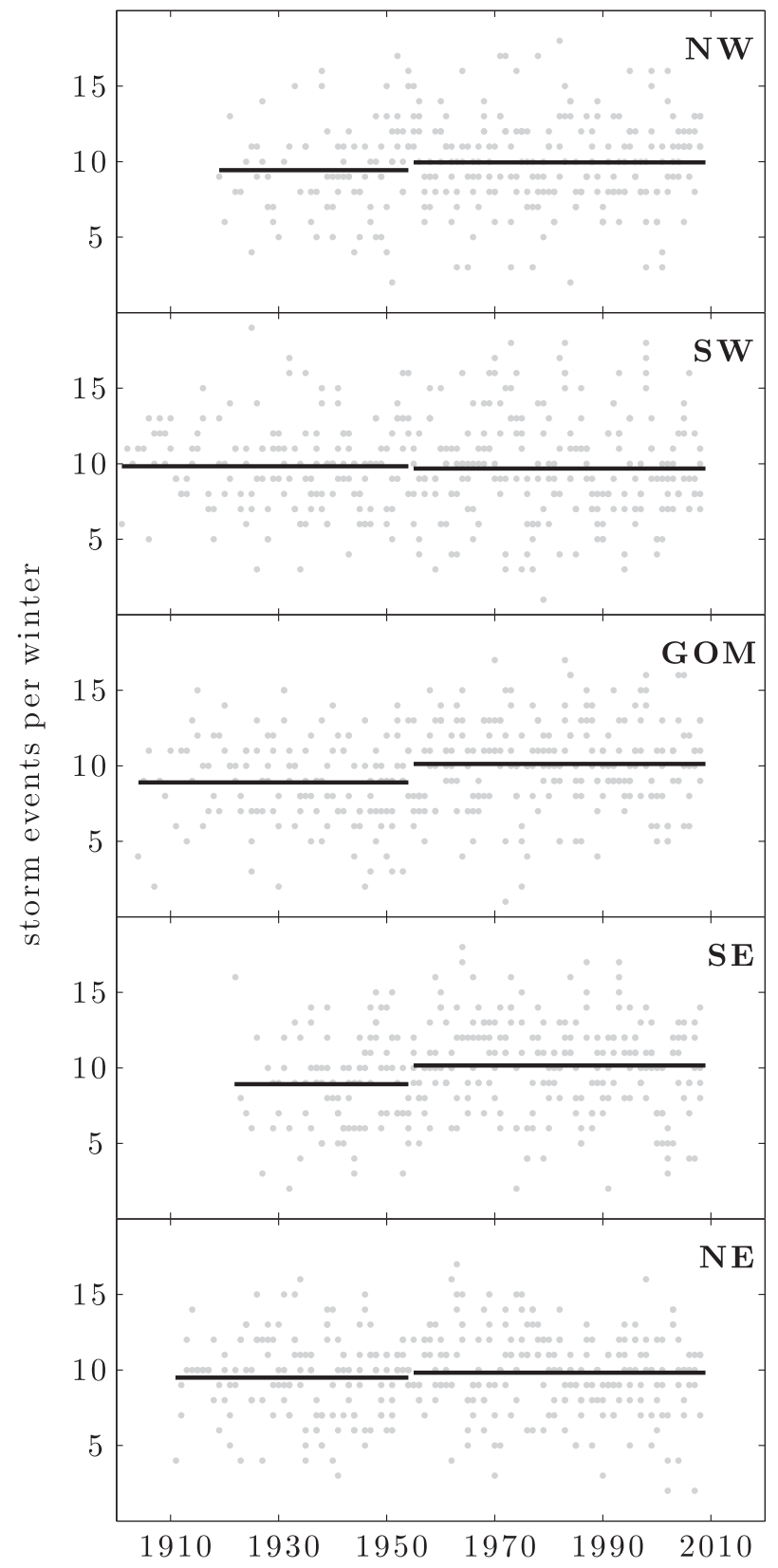

FIG. 4. The number of events extracted in each winter at each gauge (gray circles) grouped by region. Storm counts in all regions show substantial interannual variability, and two regions (GOM and SE) show a small, possibly significant low-frequency change. The low-frequency variation is illustrated by the black lines, which represent the mean number of events per winter over the length of the line.

\section{a. Interannual variability}

Interannual variability in storminess is due to a variety of factors, but one of the most important is large-scale changes in atmospheric pressure patterns and steering currents. The two primary modes used to describe 
TABLE 2. The ENSO phase of each winter was determined by a WSOI defined to be the mean of the SOI over the winter months November-April. The year of each winter is given by the year of January in each winter

\begin{tabular}{ccc}
\hline \hline Phase & Criterion & Years (January) \\
\hline Warm (El Niño) & WSOI $\leq-0.5$ & $1905-06,1912,1915,1919$, \\
& & $1926,1940-42,1952,1958$, \\
& & $1966,1973,1978,1983,1987$, \\
& & $2090,1992-95,1998,2003$, \\
Cool (La Niña) & WSOI $\geq 0.5$ & $1902,1904,1910-11,1917-18$, \\
& & $1921,1923,1925,1927-29$, \\
& & $1939,1943,1950-51,1956$, \\
& & $1962-63,1967,1971,1974$, \\
& & $1976,1989,1999-2001,2006$, \\
& & \\
& &
\end{tabular}

interannual atmospheric variability in the Northern Hemisphere are the North Atlantic Oscillation (NAO) and ENSO. We looked for relationships between storminess in tide gauges and indices of these two climate modes to assess possible causes for the observed interannual variations in storm counts from tide gauges. A significant relationship between ENSO phase and GOM cyclogenesis was found, but no significant relationship of cyclogenesis with the NAO index at interannual scales was determined. Therefore, the NAO as it relates to interannual storminess variability is not discussed further.

The ENSO phase of each winter was determined by a winter Southern Oscillation index (WSOI) defined to be the mean of the Southern Oscillation index (SOI) over the November-April period. Warm phase winters were characterized by WSOI $\leq-0.5$ and cold phase winters were characterized by WSOI $\geq 0.5$. Over the analyzed period from 1901 to 2011, there were 25 warm and 31 cold phase winters, as listed in Table 2. The SOI was chosen as a basis for determining ENSO phase, because the index is long and extends through the early twentieth century. To be sure the results were not dependent on the index itself, however, identical calculations were performed using the multivariate ENSO index (MEI; Wolter and Timlin 1993), which is the first principal component of six atmospheric and oceanic variables in the tropical Pacific. The results of our interannual analysis were not changed by replacing the SOI with the MEI over its period of availability.

Regional series of storm events per winter were created by first calculating ratios of the total number of storm events in a region during each winter to the total number of valid hours recorded by the gauges in the particular region and winter. These ratios were then multiplied by the number of hours in a winter period (November-April) to give units of events per winter. The mean number of events per winter in each region was removed, and the differences from the mean were binned and averaged according to the WSOI phase of winter.

The results of this calculation are shown in Fig. 5. Each bar represents how many more or fewer winter events are expected relative to climatology during a given ENSO phase based on our database of storms from tide gauges. The significance of these values was tested via a Monte Carlo simulation. For each simulation iteration, individual storm events in the database from a particular region were randomly reassigned to a different time and the calculations were repeated on the simulated data. Randomizing the timing of each storm removed the influence of ENSO phase on storm occurrence. Therefore, for regions in which the number of storms per winter is outside the black bars in Fig. 5, we reject the null hypothesis that ENSO does not affect winter storm activity.

Figure 5 shows a significant elevation of about two storms per winter during warm ENSO phase relative to the cold phase in both the GOM and SE regions, but no significant change was found in the NE. Results in the GOM indicate an excitation (suppression) of the GOM

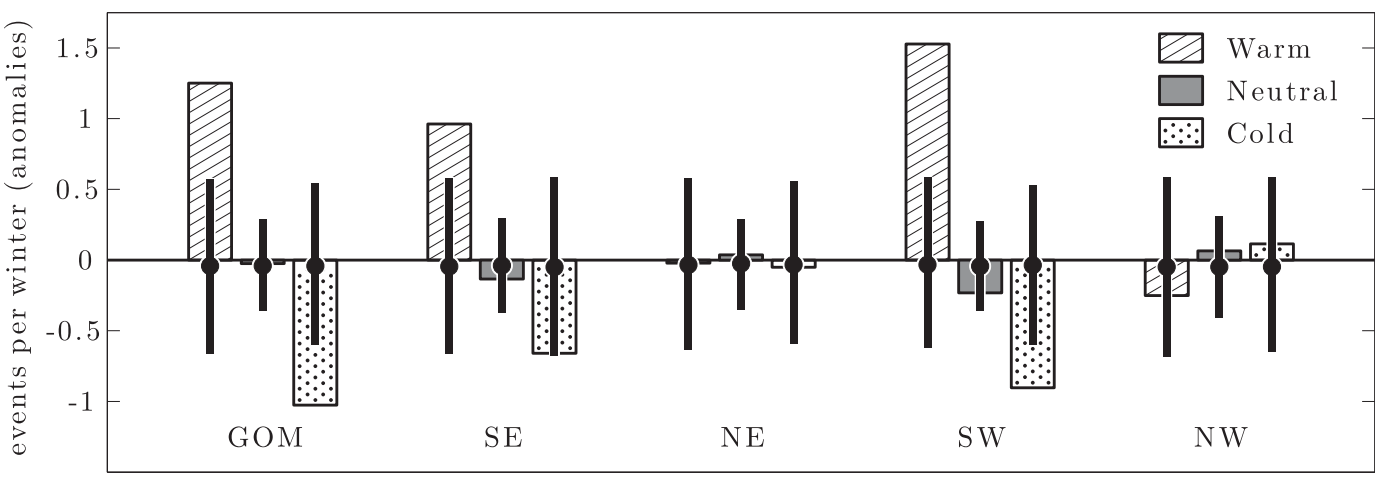

FIG. 5. Number of events per winter relative to climatology in each region partitioned by ENSO phase: warm (hatched), neutral (gray), and cold (stippled). The black circles and bars represent the median and 95\% range of values from a Monte Carlo simulation. Values outside the black bars are significant. 


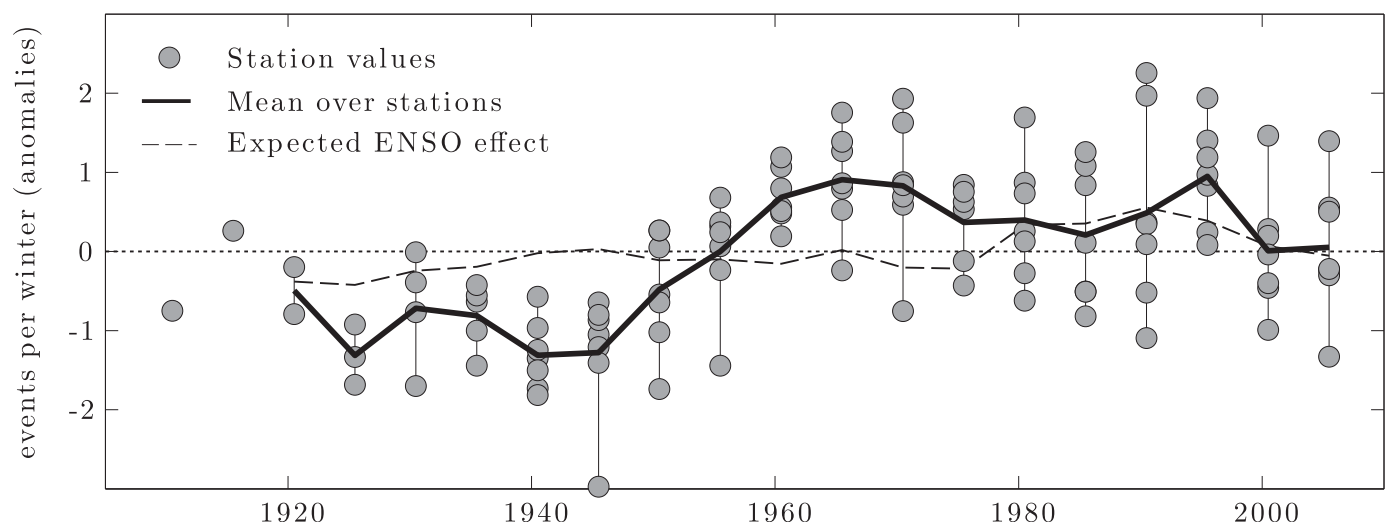

FIG. 6. The number of events per winter in overlapping 10-yr periods at each gauge (gray circles) in the GOM and SE regions. The $y$ axis reflects anomalies from the 10 storms per winter climatology. For each gauge, only decades with at least $75 \%$ temporal coverage were included in the analysis. The thick black line represents the mean over the available GOM and SE gauges for each 10-yr period. The dashed line is the estimated variability in decadal storm counts due to ENSO.

cyclogenesis region during warm (cold) phase winters, which is consistent with the results of Kennedy et al. (2007) and the effect of ENSO phase on the jet stream (e.g., Smith et al. 1998). The significant relationship between ENSO phase and events in the SW region is also consistent with the influence of ENSO on the jet stream. Results in the SE indicate that changes in GOM cyclogenesis lead to corresponding changes in storm frequency of the same sign along Atlantic portions of the SOC track.

We found the effect of warm events in particular to be about one more storm per winter than a neutral winter, which is a smaller effect than the approximately two storm increase estimated by some atmospheric studies (e.g., Noel and Changnon 1998; Hirsch et al. 2001). This is likely due to the relatively low threshold used to define a warm event in this study. If the WSOI threshold for a warm event is increased from -0.5 to -0.75 , the effect in the tide gauge analyses increases to $1.5-2$ more storms per winter in a warm event relative to neutral.

The lack of influence by either ENSO phase in the NE found here partially conflicts with the results of Sweet and Zervas (2011). The authors found an increase in storm surge events at mid-Atlantic and NE tide gauges during warm phase winters but no significant relationship between the number of surges during cool phase winters. This discrepancy may be due to differences in the methods employed by the two studies. In particular, Sweet and Zervas (2011) note the influence of warm ENSO phase on lower-frequency alongshore winds, which raise mean water levels in the region and contribute to higher surge frequency. This sort of lower-frequency variability is explicitly removed by the high-pass filter applied to the data analyzed here. The difference in methods reflects the difference in assessing variability in surge frequency versus storm frequency.
Given the consistency of the results at interannual scales with similar studies of water levels and meteorological measurements, we conclude that the methods employed in this study are valid and may be extended to longer time scales.

\section{b. Low-frequency variability}

Yearly winter storm counts in the GOM and SE regions (Fig. 4) suggest an increase in GOM cyclogenesis during the latter portion of the twentieth century. Lowfrequency changes were isolated from interannual variation in these two regions by averaging the number of events at each gauge in overlapping 10-yr intervals. The numbers of storms per winter in the 10-yr intervals are shown in Fig. 6 and exhibit a multidecadal change in the number of storm events per winter in the GOM and SE regions. This change is apparent in both the counts from individual gauges and the average over the GOM and SE regions. The storm counts show decreased storminess from the 1920s through the 1940s followed by a period of elevated storminess from the 1960s through the 1990s. The temporal resolution is very coarse, but there appears to be a zero crossing around 1955.

We used the apparent zero crossing in Fig. 6 to define periods of suppressed storminess (1920-55) and enhanced storminess (1956-2000). The number of events per winter in these two periods is shown for each gauge individually (Fig. 7a) and for each region (Fig. 7b). As mentioned in section $2 \mathrm{a}$, the long time scales considered in this portion of our analysis forced us to remove three West Coast gauges and one GOM gauge from consideration because of insufficient data in the early part of the century. The gauges deemed appropriate for the low-frequency analysis are starred in Table 1. 


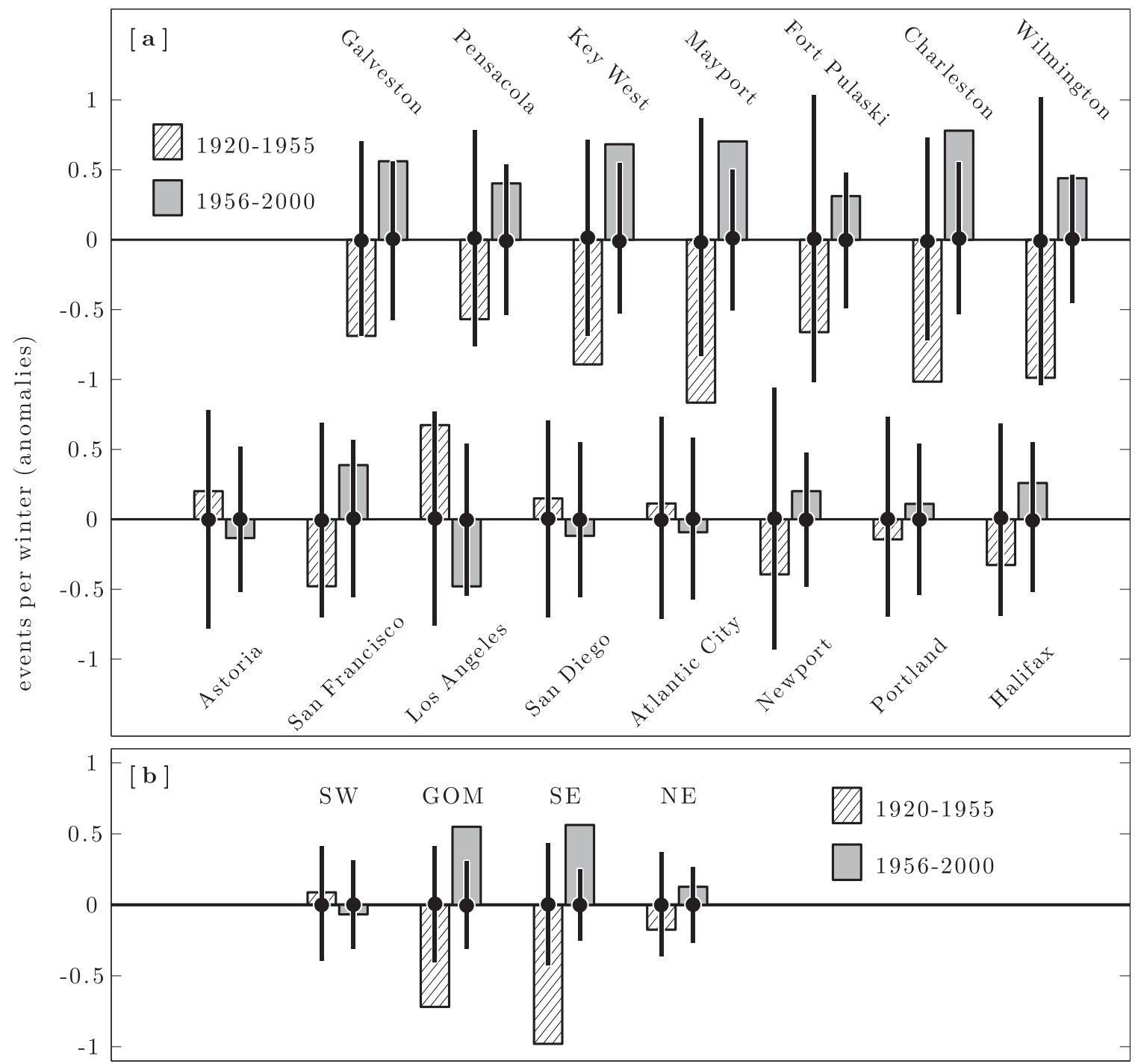

FIG. 7. Number of events per winter relative to the mean for 1920-55 (hatched bars) and 1956-2000 (gray bars). Event counts are given for (a) each individual gauge and (b) each region. The black circles and bars represent the median and $95 \%$ range of values from a Monte Carlo simulation. Values outside the black bars are significant.

The significance of the low-frequency change for each gauge and region was assessed by calculating the probability that the observed difference in storm counts between the enhanced and suppressed periods could have occurred by chance. Probabilities of the differences occurring by chance were calculated using a Monte Carlo approach $\left(10^{4}\right.$ iterations $)$ similar to the ENSO analysis above. For each iteration, storm events were randomly distributed in time and the number of events per year was calculated in each period.

The results of the statistical analysis in Fig. 7a show the increase in storm activity from $1920-55$ to $1956-2000$ was statistically significant $(>95 \%)$ for four out of the seven gauges in the GOM and SE. The other three gauges were consistent in sign. In the $\mathrm{NE}$ and on the West Coast, probabilities were large that the small difference in storm counts between the two periods occurred by chance. A more effective measure of significance, however, is to examine the significance of a composite analysis over the available gauges in each region (Fig. $7 b$ ). The composite analysis shows a 1-1.5 events per year increase in the GOM and SE from the early to late twentieth century that is highly significant. We note, however, that the significance for the regional calculations was calculated by randomizing the identified storms at each gauge independently.

We interpret the significant multidecadal increase in storm events from GOM and SE gauges as not just an 

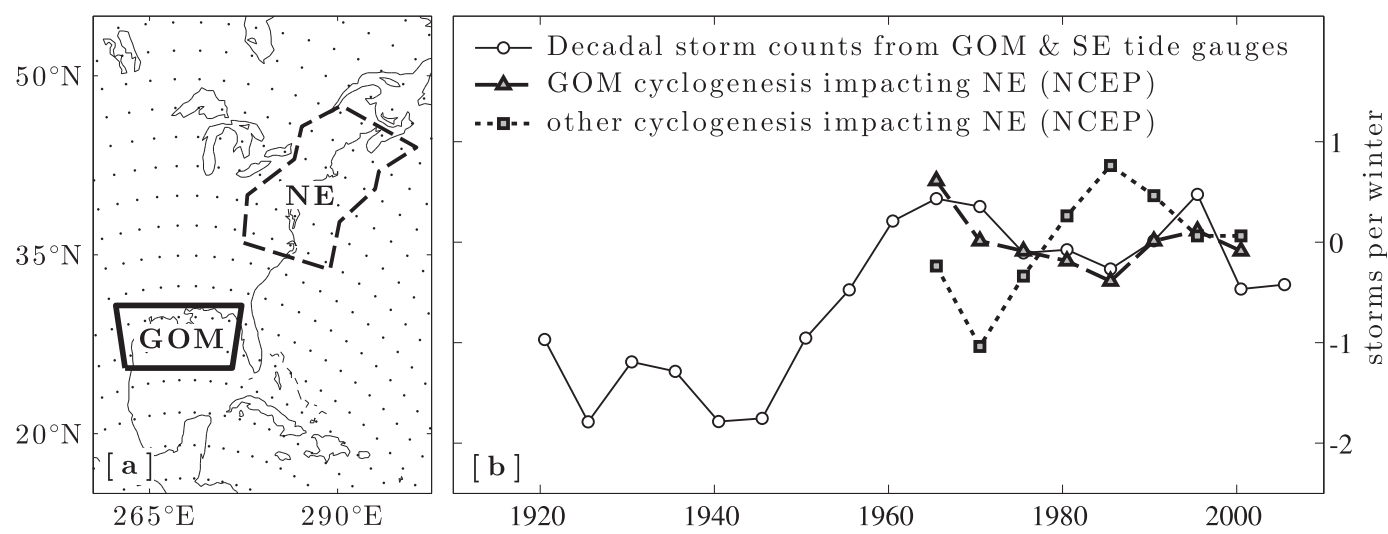

FIG. 8. (a) The NE and GOM regions defined for the analysis of the storm-track data. (b) Decadal storm counts from the GOM and SE regions (solid line with circles), GOM cyclogenesis resulting in storms that enter the NE region (dashed line with triangles), and cyclogenesis outside the GOM region resulting in storms that enter the NE region (dotted line with squares). The mean of each series over the common period is removed.

increase in GOM cyclogenesis but in particular as an increase in the number of winter storms that form in the GOM and track along the Atlantic coast of North America. In other words, we hypothesize that the multidecadal change indicates an increase in storms that follow a track similar to the SOC in Fig. 1. The reason for this hypothesis is that the increase occurred not only in the GOM but also the SE region as well, which indicates that the storms forming in the GOM propagate to the Northeast along the Atlantic coast. However, the lack of significant change in the NE region appears to be in conflict with this hypothesis. We therefore pose a secondary hypothesis that there must be a compensating multidecadal decrease in cyclogenesis affecting the NE in regions other than the GOM.

Evaluating these two hypotheses is difficult given the temporal limitations of meteorological data during the twentieth century. However, there are smaller decadal fluctuations in the storm counts during the second half of the century (Fig. 6), which may be assessed to infer the nature of the longer-term variability. For this analysis, we analyzed a database of Northern Hemisphere cyclone locations and characteristics derived from the NCEP-NCAR reanalysis and housed by the National Snow and Ice Data Center (NSIDC) (Serreze 2009). In this dataset, the NCEP-NCAR sea level pressure fields are interpolated to a $250 \mathrm{~km} \times$ $250 \mathrm{~km}$ version of the NSIDC Equal-Area Scalable Earth Grid (EASE-Grid) (Armstrong and Brodzik 1995) and the detection and tracking algorithm of Serreze et al. (1997) is used to identify storms over the 51-yr period spanning 1958-2008. A portion of the grid is shown by the black dots in Fig. 8a, and cyclogenesis for any particular storm is defined to be the first instance of a closed 1-hPa isobar.
To test the assertion that the decadal time series of GOM and SE storm counts represents storms with a similar track to that of the SOC, we first identified all storms entering the NE region (dashed line Fig. 8a) for which cyclogenesis occurred in the GOM (solid line Fig. 8a). Decadal counts for such storms from the track data are shown in Fig. $8 \mathrm{~b}$ with the same decadal tide gauge counts from Fig. 6. During the common period the two curves agree quite well considering the vastly different data sources and methods involved in creating the two time series. Given the agreement, we conclude that the decadal storm counts from GOM and SE tide gauges do in fact represent, to good approximation, storms with a similar track to the SOC.

This leaves the question of why there is no significant change in the $\mathrm{NE}$ if there are more storms following a track similar to the SOC. To resolve the apparent contradiction, we created decadal counts of storms impacting the NE region due to cyclogenesis in areas outside the GOM. The result is shown in Fig. 8b, and the curve varies out of phase with both the tide gauge counts and the storm tracks originating in the GOM. This relationship supports our second hypothesis above that the decadal variability in GOM cyclogenesis in the second half of the twentieth century largely reflects a redistribution of cyclogenesis between the GOM and other regions. The out of phase relationship also contradicts an alternative hypothesis that the multidecadal change in the GOM and SE regions is due to storms that simply propagate eastward over the ocean before impacting the NE. If this were the case, the decadal variability would manifest in the GOM cyclogenesis curve only and not in the curve of cyclogenesis in other regions. We thus conclude that the lack of multidecadal change in storm events detected at NE gauges is not inconsistent with 


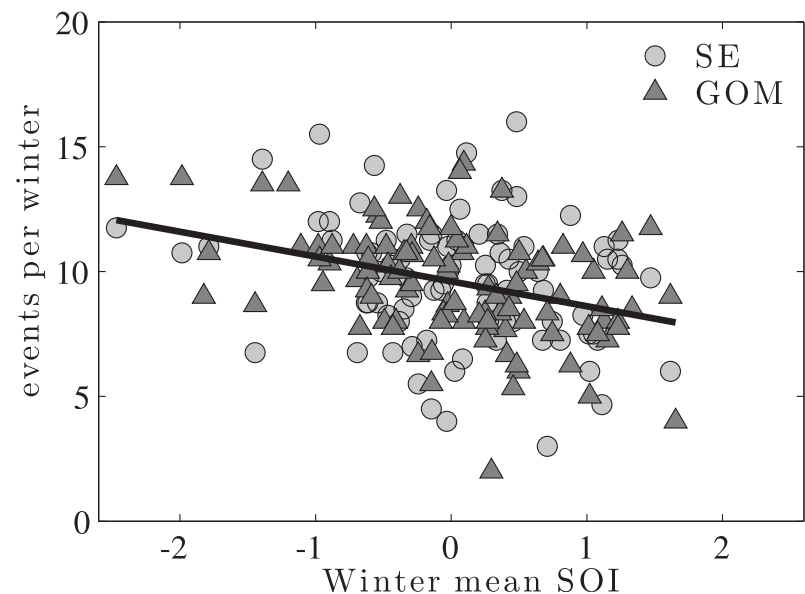

FIG. 9. The number of events in individual winters vs the WSOI index in the GOM (triangles) and SE (circles) regions. The solid black line is a best fit to the combined GOM and SE values with $R^{2}=0.12$. The $R^{2}$ value is significant at the $99 \%$ level based on a $t$ statistic, which is a valid test because the yearly counts from the GOM and SE regions are approximately normally distributed.

a multidecadal increase in activity along the SOC track. Finally, by combining the two results from the stormtrack data, we can infer that the multidecadal increase in activity along the SOC track is not likely due to an overall increase in the number of storms over eastern North America but rather an increased tendency for the winter storms to form in the GOM at the expense of other cyclogenesis regions.

\section{c. A low-frequency mechanism}

Given the connection of ENSO to storminess over North America (e.g., Hirsch et al. 2001; Schubert et al. 2005; Eichler and Higgins 2006; Kennedy et al. 2007; Sweet and Zervas 2011; this paper), it was logical to ask if the observed multidecadal change in GOM cyclogenesis was the result of low-frequency variation in ENSO. We tested this hypothesis in two ways. First, we simply tallied the number of warm and cold phase winters in each 10-yr period as prescribed in Table 2. We then estimated the effect of ENSO given that our results indicated about one more (less) storm than average is expected during a warm (cold) phase winter in the GOM and SE regions. This method only assesses the effect of ENSO phase, however, and does not allow for variability due to the magnitude of the event. Thus, we also estimated the effect of ENSO in the GOM and SE regions via a linear regression of the number of events in individual winters from the GOM and SE regions onto the WSOI index (Fig. 9). The regression coefficient for the slope of the black line in Fig. 9 is -0.99 events per unit WSOI. We then estimated the effect of ENSO on the multidecadal variability by multiplying the WSOI by this coefficient and creating decadal averages of the resulting time series. Both methods of estimating the long-term effect of ENSO produced similar curves, but neither produced the magnitude or timing of zero crossings in the decadal storm counts. The estimated ENSO effect from the regression was slightly larger in magnitude, and it is shown with the decadal storm counts in Fig. 6 for comparison.

A second argument against attributing the lowfrequency change to ENSO follows from results in the SW region. Storminess in the SW region, as in the GOM and $\mathrm{SE}$ regions, was found to be significantly enhanced during warm ENSO phase relative to the cold phase. This result is consistent with the well-documented dependence of jet stream position and character over North America on the phase of ENSO. However, at multidecadal time scales, there is no significant change in the SW region. This contrasts with the multidecadal increase of storm activity in the GOM and SE regions and suggests that a mechanism other than ENSO is responsible for the multidecadal change in the GOM and SE regions.

An alternative explanation for the difference between the east and west coasts on longer time scales is a tendency for the jet stream to meander about its mean position as opposed to shifting latitudinally as a result of changing ENSO phase. Meandering gives the jet stream a north-south orientation over the United States, allowing frontal systems to reach the GOM and interact with oceanic energy sources in the GOM and Gulf Stream regions. The merit of the meander mechanism was investigated using $5^{\circ} \times 5^{\circ}$ sea level pressure (SLP) fields over North America during the twentieth century from the second Hadley Centre Sea Level Pressure dataset (HadSLP2) (Allan and Ansell 2006). We note that SLP cannot give the exact position of the jet stream in the upper troposphere. However, the jet stream is a feature of the boundary between the subtropical and subpolar air masses, and low-frequency changes in the large-scale horizontal structure of the SLP field do provide information about the slowly varying mean position of the jet stream. HadSLP2 was chosen because it spans the time period of the low-frequency storminess variation.

Figure 10 shows the winter SLP difference over North America between the periods of enhanced (1956-2000) and suppressed (1920-55) cyclogenesis in the GOM. The pattern shows the polar high was stronger and penetrated further south over eastern Canada during the latter portion of the twentieth century. In addition, SLP was lower over the continental United States during the same period. This pattern is consistent with the jet stream persistently meandering southward over eastern North America during the time of enhanced GOM 


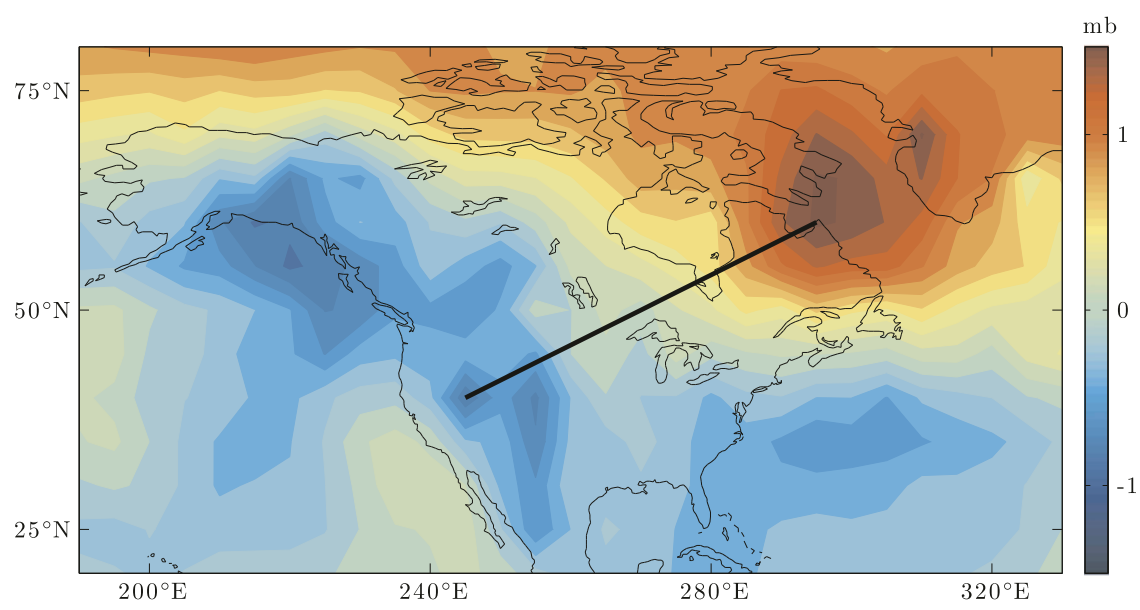

FIG. 10. The difference in mean winter (November-April) SLP between the periods 19562000 and $1920-55$. The $5^{\circ} \times 5^{\circ}$ gridded SLP fields are from HadSLP2 (Allan and Ansell 2006). The SLP gradient along the thick black line was used to create a temporal representation of the amplitude of this pattern.

cyclogenesis. A southern meander not only brings enhanced synoptic energy to the GOM and SE regions, but the injection of cold polar air enhances the potential for cyclogenesis because of increased baroclinicity at the coast due to the disparity in heat capacity between land and sea (Resio and Hayden 1975; Dickson and Namias 1976).

Temporal variations in the amplitude of the SLP pattern were calculated from the mean gradient of the SLP field along the thick black line in Fig. 10 during the overlapping 10-yr intervals used for storm counts. The line was chosen to be across the gradient and intersect the centers of action in the SLP pattern over northeastern and southwestern North America. A steeper gradient was interpreted as intensification of the SLP pattern. Decadal averages of the SLP gradient and the number of storms per winter in overlapping $10-\mathrm{yr}$ periods are plotted together in Fig. 11. The two series were leveled over the period 1920-50 for each curve (dashed line), because during the period when the SLP gradient along the line is weak (i.e., there is no meander) we expect there to be little relationship between GOM cyclogenesis and the gradient. In other words, the suppressed period may be interpreted as random variation about some base state. The correlation between these two series is moderate $(R=0.7)$; however, the relationship is clearly better during the period of enhanced storminess. It is logical to expect the correlation to be best when the strength of the SLP gradient along the line is most positive, because the pattern only affects GOM cyclogenesis if it is active. Given the length of the time series and the long time scale of the variation, the number of degrees of freedom is small and it is difficult to assess the significance of the correlation. We do not consider this correlation to be definitive, but argue that it does support our suggestion.

\section{Discussion}

The multidecadal change in GOM cyclogenesis was not previously identified in modern meteorological products (e.g., Hirsch et al. 2001), because the gridded fields are limited temporally to the second half of the twentieth century. Thus, a multidecadal change in storm frequency with a zero crossing in the 1950s, such as that shown in Fig. 6, would not be identified in gridded reanalyses. In addition, other studies of East Coast storminess predating gridded meteorology products found results compatible with increased SOC track activity during the twentieth century. Most notably, Hayden (1981) found a similar increase in storm frequency over GOM and East Coast marine areas from the 1910s through the 1970s with a peak in the 1960s, which is consistent with our results.

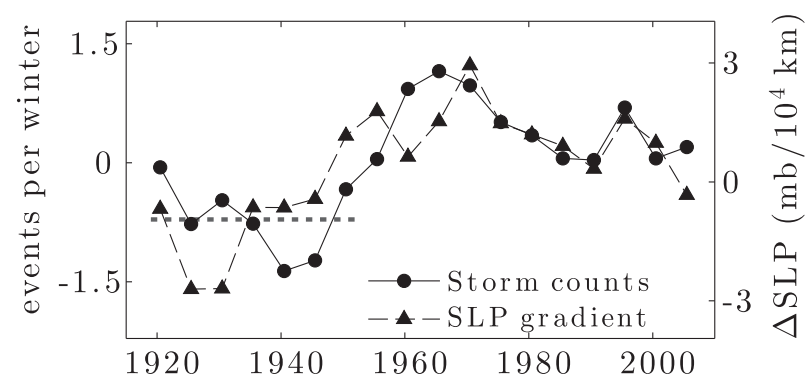

FIG. 11. The number of GOM and SE storms per winter in overlapping 10-yr periods from Fig. 6 (solid line with circles) and the decadal average of the SLP gradient during winter along the line in Fig. 10 (dashed line with triangles). The two are plotted such that the means of both series for 1920-50 are represented by the dashed gray line. 

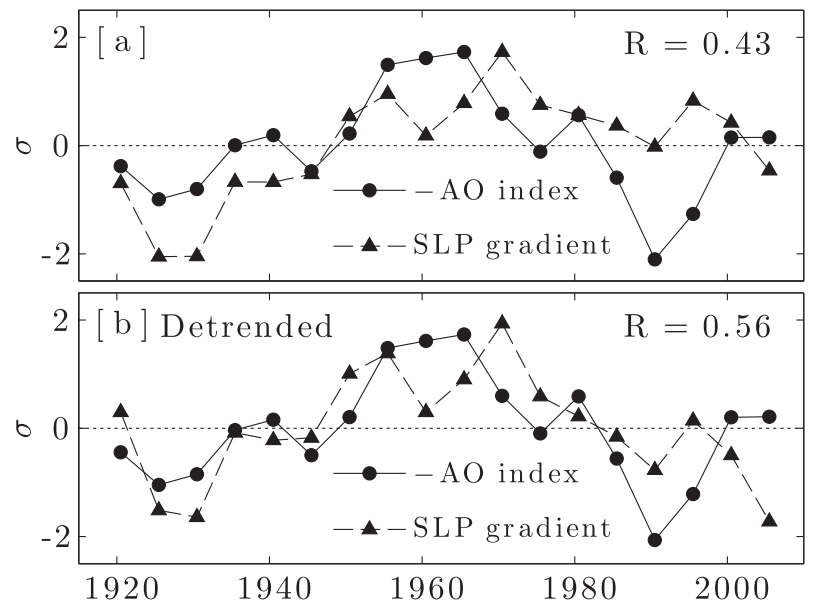

FIG. 12. The relationship of the SLP gradient to the Arctic Oscillation. (a) Decadal averages for both the SLP gradient (dashed line with triangles) and the winter AO index (solid line with circles). The sign of the AO has been switched, such that the negative phase of the AO corresponds to increased amplitude of the SLP pattern. (b) The same two series detrended.

The winter of 2009/10 in the southeast United States was characterized by record cold temperatures and snowfall associated with multiple winter storms. The severe winter in the region was due in part to an extreme negative phase of the Arctic Oscillation and the associated northward redistribution of atmospheric mass (Cohen et al. 2010). We explored the relationship between low-frequency variability in the phase of the Arctic Oscillation (AO) and the SLP gradient over North America. The AO is defined as the amplitude of the first EOF mode of SLP poleward of $20^{\circ} \mathrm{N}$ in the NCEP reanalysis and it is extended into the early twentieth century by projecting the AO mode onto the SLP anomalies from weather stations (Thompson and Wallace 2000). A winter AO index was created by averaging the AO over each November-April season. Decadal averages of the winter AO are shown with decadal averages of the SLP gradient in Fig. 12a. Figure $12 \mathrm{~b}$ shows detrended versions of the same two series in Fig. 12a, which we show because it was not clear whether detrending the series was appropriate. In general, the largest amplitudes of the SLP pattern are found during decades when the winter $\mathrm{AO}$ is most negative. The correlation between the decadal averaged winter $\mathrm{AO}$ and the SLP gradient in the case when trends are not removed is not large $(-0.4)$, but it is significantly different from zero with greater than $90 \%$ confidence. Detrending the series does not substantially change the correlation. The significance is based on identical decadal averaging calculations in a Monte Carlo test using realizations of red noise series with spectral slopes identical to the AO and SLP gradient series. The significance does suggest that the AO may be a partial contributor to the decadal changes in SLP over North America, but we consider the relationship to be speculative.

Due to the multidecadal time scale and length of the tide gauge records, it is not possible to confidently classify the low-frequency change in GOM cyclogenesis as either oscillatory or trend like. Multiple modeling studies (e.g., Yin 2005; Bengtsson et al. 2006) show a tendency for the jet stream to shift north in a warming climate, which would seem to argue against linking our results to twentiethcentury climate trends. It is important to note, however, that such conclusions about jet stream position in models are in a zonally averaged sense and do not necessarily apply to any particular region.

\section{Conclusions}

High-passed sea level records from tide gauges were used to count storms and assess twentieth century variability of winter storm frequency over the eastern United States. To validate our methods, we first confirmed the dependence of winter storm frequency on ENSO phase identified by multiple authors in the literature. The primary result of this study is a multidecadal increase in storm frequency from early to late twentieth century along the Gulf of Mexico (GOM) and Southeast (SE) U.S. coasts. We also confirmed the results of Zhang et al. (2000), who found no long-term change in storminess in the U.S. Northeast from tide gauges.

We interpret the multidecadal increase in the GOM and SE regions as an increase in synoptic activity along a storm track similar to that of the Storm of the Century (SOC) shown in Fig. 1. The lack of significant change in the NE appears to contradict this interpretation, but independent analysis of storm-track data from sea level pressure (SLP) fields over the second half of the century reveal that increased winter cyclogenesis in the GOM may be compensated by decreased cyclogenesis in other regions, resulting in no net effect on storminess in the NE. Thus, we conclude that the multidecadal increase in activity along the SOC track from GOM and SE gauges is not likely to indicate an increase in total winter storminess over the eastern United States but rather an increased tendency for storms to be generated in the GOM at the expense of other cyclogenesis regions.

Furthermore, we propose the multidecadal increase in GOM cyclogenesis and activity along the SOC track is related to an increased tendency for the jet stream to meander south over the eastern United States since the 1950s. This mechanism is supported by the difference in SLP over North America from the early to the late twentieth century (Fig. 10), and the SLP pattern is related 
to the multidecadal change in GOM cyclogenesis when the pattern is strongest (Fig. 11). It is not clear if the multidecadal change in storminess is oscillatory or trend like because of the long time scale of the variation.

Acknowledgments. We thank three anonymous reviewers for insightful comments and suggestions that significantly enhanced this work.

\section{REFERENCES}

Allan, R. P., and T. Ansell, 2006: A new globally complete monthly historical gridded mean sea level pressure dataset (HadSLP2): 1850-2004. J. Climate, 19, 5816-5842.

Armstrong, R., and M. Brodzik, 1995: An earth-gridded SSM/I data set for cryospheric studies and global change monitoring. Adv. Space Res., 16, 155-163, doi:10.1016/0273-1177(95)00397-W.

Bengtsson, L., K. I. Hodges, and E. Roeckner, 2006: Storm tracks and climate change. J. Climate, 19, 3518-3543.

Businger, S., D. I. Knapp, and G. F. Watson, 1990: Storm following climatology of precipitation associated with winter cyclones originating over the Gulf of Mexico. Wea. Forecasting, 5, 378-403.

Carter, D. J. T., and L. Draper, 1988: Has the north-east Atlantic become rougher? Nature, 332, 494, doi:10.1038/332494a0.

Cohen, J., J. Foster, M. Barlow, K. Saito, and J. Jones, 2010: Winter 2009-2010: A case study of an extreme Arctic Oscillation event. Geophys. Res. Lett., 37, L17707, doi:10.1029/ 2010GL044256.

Davis, R. E., G. Demme, and R. Dolan, 1993: Synoptic climatology of Atlantic coast north-easters. Int. J. Climatol., 13, 171-189, doi:10.1002/joc.3370130204.

DeGaetano, A. T., M. E. Hirsch, and S. J. Colucci, 2002: Statistical prediction of seasonal East Coast winter storm frequency. J. Climate, 15, 1101-1117.

Dickson, R. R., and J. Namias, 1976: North American influences on the circulation and climate of the North Atlantic sector. Mon. Wea. Rev., 104, 1255-1265.

Eichler, T., and R. W. Higgins, 2006: Climatology and ENSO-related variability of North American extratropical cyclone activity. J. Climate, 19, 2076-2093.

Foreman, M. G. G., 1977: Manual for tidal heights analysis and prediction. Institute of Ocean Sciences Pacific Marine Science Rep. 77-10, 58 pp.

Hayden, B. P., 1981: Secular variation in Atlantic coast extratropical cyclones. Mon. Wea. Rev., 109, 159-167.

Hirsch, M. E., A. T. DeGaetano, and S. J. Colucci, 2001: An East Coast winter storm climatology. J. Climate, 14, 882-899.

Hosler, C. L., and L. A. Gamage, 1956: Cyclone frequencies in the United States for the period 1905 to 1954. Mon. Wea. Rev., 84, 388-390.

Kennedy, A. J., M. L. Griffin, S. L. Morey, S. R. Smith, and J. J. O'Brien, 2007: Effects of El Niño-Southern Oscillation on sea level anomalies along the Gulf of Mexico coast. J. Geophys. Res., 112, C05047, doi:10.1029/2006JC003904.

Kocin, P. J., P. N. Schumacher, R. F. Morales Jr., and L. W. Uccellini, 1995: Overview of the 12-14 March 1993 superstorm. Bull. Amer. Meteor. Soc., 76, 165-182.

Lewis, J. K., and S. A. Hsu, 1992: Mesoscale air-sea interactions related to tropical and extratropical. J. Geophys. Res., 97 (C2), 2215-2228.
Mather, J. R., H. Adams, and G. A. Yoshioka, 1964: Coastal storms of the eastern United States. J. Appl. Meteor., 3, 693-706.

Noel, J., and D. Changnon, 1998: A pilot study examining U.S. winter cyclone frequency patterns associated with three ENSO parameters. J. Climate, 11, 2152-2159.

Pawlowicz, R., B. Beardsley, and S. Lentz, 2002: Classical tidal harmonic analysis including error estimates in MATLAB using T_TIDE. Comput. Geosci., 28, 929-937.

Petterssen, S., 1941: Cyclogenesis of southeastern United States and the Atlantic coast. Bull. Amer. Meteor. Soc., 22, 269-270.

_ 1950: Some aspects of the general circulation of the atmosphere. Centernary Proceedings of the Royal Meteorological Society, Royal Meteorological Society, 120-155.

Reitan, C. H., 1974: Frequencies of cyclones and cyclogenesis for North America, 1951-1970. Mon. Wea. Rev., 102, 861-868.

_ 1979: Trends in the frequencies of cyclone activity over North America. Mon. Wea. Rev., 107, 1684-1688.

Resio, D. T., and B. P. Hayden, 1975: Recent secular variations in mid-Atlantic winter extratropical storm climate. J. Appl. Meteor., 14, 1223-1234.

Schubert, S. D., Y. Chang, M. Suarez, and P. Pegion, 2005: On the relationship between ENSO and extreme weather over the contiguous U.S. CLIVAR Variations, Vol. 3, No. 3, U.S. CLIVAR Office, Washington, D.C., 1-4.

Serreze, M. C., 2009: Northern Hemisphere cyclone locations and characteristics from NCEP/NCAR reanalysis data. National Snow and Ice Data Center, Boulder, CO, digital media. [Available online at http://nsidc.org/data/nsidc-0423.html.]

_, F. Carse, R. G. Barry, and J. C. Rogers, 1997: Icelandic low cyclone activity: Climatological features, linkages with the NAO, and relationships with recent changes in the Northern Hemisphere circulation. J. Climate, 10, 453-464.

Smith, S. R., P. M. Green, A. P. Leonardi, and J. J. O. Brien, 1998: Role of multiple-level tropospheric circulations in forcing ENSO winter precipitation anomalies. Mon. Wea. Rev., 126, 3102-3116.

Sweet, W. V., and C. Zervas, 2011: Cool-season sea level anomalies and storm surges along the U.S. East Coast: Climatology and comparison with the 2009/10 El Niño. Mon. Wea. Rev., 139, 2290-2299.

Thompson, D. W. J., and J. M. Wallace, 2000: Annular modes in the extratropical circulation. Part I: Month-to-month variability. J. Climate, 13, 1000-1016.

Wang, W., W. D. Nowlin, and R. O. Reid, 1998: Analyzed surface meteorological fields over the northwestern Gulf of Mexico for 1992-94: Mean, seasonal, and monthly patterns. Mon. Wea. Rev., 126, 2864-2883.

Whittaker, L. M., and L. H. Horn, 1981: Geographical and seasonal distribution of North American cyclogenesis, 1958-1977. Mon. Wea. Rev., 109, 2312-2322.

Wolter, K., and M. S. Timlin, 1993: Monitoring ENSO in COADS with a seasonally adjusted principal component index. Proc. 17th Climate Diagnostics Workshop, Norman, OK, NOAA/ $\mathrm{NMC/CAC,} \mathrm{52-57.}$

Yin, J. H., 2005: A consistent poleward shift of the storm tracks in simulations of 21 st century climate. Geophys. Res. Lett., 32, L18701, doi:10.1029/2005GL023684.

Zhang, K., B. C. Douglas, and S. P. Leatherman, 2000: Twentiethcentury storm activity along the U.S. East Coast. J. Climate, 13, 1748-1761.

Zishka, K. M., and P. J. Smith, 1980: The climatology of cyclones and anticyclones over North America and surrounding ocean environs for January and July, 1950-77. Mon. Wea. Rev., 108, 387-401. 